\title{
Pós-graduação em Educação: a Dialética da Teoria e Método
}

\author{
Graduate Program in Education: \\ The Dialetic of Theory and Method
}

\author{
Maria de Fátima Cardoso GOMES ${ }^{1}$ \\ Denise Alves ARAÚJO²
}

\begin{abstract}
Resumo
Este artigo discute a articulaçáo entre a Teoria Histórico-cultural e a Etnografia em Educação, pressupostos teórico-metodológicos para pesquisas em sala de aula. A dialética entre teoria e método é apresentada com base em pesquisa realizada na sala de aula da Educaçáo de Jovens e Adultos, em Belo Horizonte, no ano de 2015. Os eventos analisados revelam como professora e estudantes das turmas pesquisadas produziram sentidos para conceitos matemáticos. Os resultados revelaram a cognição social situada como algo que não ocorre dentro das mentes das pessoas, mas que se constitui nas suas vivências, mediada pela instrução escolar.
\end{abstract}

Palavras-chave: Dialética. Teoria e método. Teoria Histórico-cultural. Etnografia em Educação.
This article discusses the relationship between the Cultural-Historical Theory and the Ethnography in Education, theoretical and methodological assumptions for research in the classroom. The dialectic between theory and method is presented based on research conducted in the Youth and Adult Education classroom, in Belo Horizonte, in 2015. The events analyzed show how the teacher and the students of the researched groups produced senses to mathematical concepts. The results revealed social cognition situated as something that does not occur within the minds of people, but is constituted in their experiences, and mediated by schooling.

Keywords: Dialetic. Theory and Method. Cultural Historical Theory. Ethnography in Education.

1 Pós-Doutorada em Linguística Aplicada pelo Instituto de Estudos Linguísticos (IEL) da Universidade Estadual de Campinas (UNICAMP). Professora da Faculdade de Educação e do Programa de PósGraduação em Educação da Universidade Federal de Minas Gerais (UFMG). Coordenadora do Grupo de Pesquisas e Estudos de Psicologia Histórico-Cultural na Sala de Aula (GEPSA), vinculado ao Laboratório de Psicologia da Educação Helena Antipoff (LAPED). Pesquisadora do Centro de Alfabetização Leitura e Escrita (CEALE). E-mail: mafacg@gmail.com ou mafa@fae.ufmg.br

2 Doutora em Educação pelo Programa de Pós-Graduação em Educação: Conhecimento e Inclusão Social (FAE-UFMG), na linha de pesquisa Psicologia e Psicanálise em Educação. Professora do Núcleo de Matemática do Centro Pedagógico da UFMG. Participa do Projeto de ensino, pesquisa e extensão Nossa Escola Pesquisa Sua Opinião (NEPSO). E-mail: daalves@usp.br

R. Educ. Públ.
Cuiabá

v. 28

ก. 68 p. $441-463$ maio/ago. 2019 


\section{Introdução}

Este artigo pretende discutir a dialética da teoria e método, tendo como base uma pesquisa realizada em sala de aula de Educação de Jovens e Adultos (EJA), em Belo Horizonte, em que professora e estudantes produziam sentidos para o ensino de fraçóes. Para isso, o Grupo de Estudos e Pesquisa em Psicologia Histórico-cultural na Sala de Aula (GEPSA) ${ }^{3}$ parte do pressuposto de que as relaçóes entre teoria e método em pesquisa educacional devem ser analisadas dialética e não mecanicamente. De acordo com Vigotski (1995, p. 47), "método é ao mesmo tempo, premissa e produto, ferramenta e resultado da investigaçáo e tem de se adequar ao objeto de estudo.” Dessa forma, em nossas produçóes acadêmicas, sejam dissertações, teses, livros, sejam artigos, fazemos um capítulo de pressupostos teórico-metodológicos e não dois capítulos separados - um de pressupostos teóricos e outro de pressupostos metodológicos. A escrita de um capítulo de pressupostos teórico-metodológicos tem base nos pressupostos da Psicologia Histórico-cultural e da Etnografia em Educação, abordagens que apresentaremos a seguir, pois elas nos ajudaram a desenvolver uma lógica de investigação histórico-cultural e, portanto, dialética, na análise dos eventos da sala de aula de Educação de Jovens e Adultos, no ano de 2015.

\section{Psicologia Histórico-cultural e Etnografia em Educação}

Iniciamos essa discussão explicitando porque fazemos uso da Psicologia Histórico-cultural e não da Psicologia sócio-histórica ou sociocultural, ou ainda sóciointeracionista, para nomearmos a teoria de Vigotski, pois o uso de uma dessas nomeaçóes revela compreensóes diferentes da mesma teoria. Em 1929, Vigotski esboça um Manuscrito que foi publicado, pela primeira vez, em 1989, em inglês, na revista Soviet Psychology (v. 27, n. 2, p. 53-77) por A. A. Puzyrei, com o título Concrete Human Psychology, que expressa os postulados fundamentais de sua teoria Histórico-cultural (VIGOTSKI, 2000, p. 10).

No ano 2000, esse manuscrito de Vigotski é publicado no Brasil, em português, em edição especial do Caderno Cedes/UNICAMP, n. 71, apresentando, ainda, artigos escritos por brasileiros estudiosos de sua teoria, discutindo os conceitos principais de sua obra. O título dessa edição especial

3 Agradecemos ao CNPq e CAPES pelo apoio financeiro às nossas pesquisas. 
do Caderno Cedes é: VIGOTSKI - O Manuscrito de 1929: temas sobre a constituição cultural do homem.

O subtítulo já nos sugere que a palavra cultural é central na obra de Vigotski para entender a constituição do ser humano como tal. E que deve ser incorporada à nomeação de sua teoria. A primeira notação do manuscrito será aqui copiada para nos ajudar a argumentar a nomeação de sua teoria como Histórico-cultural. Nas palavras de Vigotski (2000):

A palavra história (psicologia histórica) para mim significa duas coisas: 1) abordagem dialética geral das coisas neste sentido qualquer coisa tem sua história; 2) história no próprio sentido, isto é a história do homem. Primeira história $=$ materialismo dialético, a segunda $=$ materialismo histórico. As funçốes superiores diferentemente das inferiores, no seu desenvolvimento, são subordinadas às regularidades históricas (veja o caráter dos gregos e o nosso). Toda a peculiaridade do psiquismo do homem está em que nele são unidas (síntese) uma e outra história (evoluçáo + história). (VIGOTSKI, 2000, p. 23).

Continuando a reflexão sobre o desenvolvimento Histórico-cultural do homem, Vigotski vai afirmar:

[...] todo desenvolvimento cultural passa por 3 estágios: em si, para outros, para si - ver o exemplo do gesto indicativo inicialmente apenas um movimento de agarrar mal sucedido, direcionado para um objeto que marca a ação; depois a mãe entende-o como indicação; depois a criança começa a indicar... Isto é, para si. (VIGOTSKI, 2000, p. 24).

Dessa forma, de acordo com Luria e Vigotski, há que se considerar o desenvolvimento histórico e cultural do homem, pois nesse desenvolvimento ocorreram "mudança e desenvolvimento não só nas relaçôes externas entre as pessoas e no relacionamento do homem com a natureza; o próprio homem, sua natureza mesma, mudou e desenvolveu-se." (LURIA; VIGOTSKI, 1995, p. 95). Do ponto de vista epistemológico, a teoria Histórico-cultural adota uma perspectiva genética de análise do desenvolvimento humano. Diferencia o biológico do cultural e compreende essas relaçóes de forma dialética, o que implica aceitar contradiçóes, idas e vindas, avanços e retrocessos nesse desenvolvimento, evolução, involução e revolução, de acordo com Vigotski (1991, 1995). Esse autor trabalha com quatro domínios genéticos para 
entender o desenvolvimento infantil e do ser humano: filogênese (estudo genético da espécie humana), ontogênese (estudo genético do ser humano), sociogênese (estudo da história cultural do homem) e microgênese (estudo de um grupo cultural específico). Micro não quer dizer pequeno, mas sim que o foco está estabelecido e que o fenômeno será estudado num tempo histórico definido, mas constantemente em movimento. Segundo Oliveira (2009) e Góes (2000), o quarto domínio genético, a microgênese, foi apresentado por Vigotski pouco antes de morrer para rejeitar a visão determinista de desenvolvimento humano, tanto biológico quanto cultural e, assim, procurar compreender as idiossincrasias, o inesperado, as particularidades de cada grupo cultural ou comunidade cultural, aproximando-se dos estudos antropológicos de sua época.

Isso nos leva a retomar a posição crítica e de negação de Vigotski em relação à teoria da recapitulação, que diz: "a evolução ontogenética, isto é, a evolução de cada ser, desde a fecundação até o nascimento, seria uma recapitulação da evolução filogenética, que é a evolução das espécies ao longo dos tempos geológicos." (BRANCO, 1994, p. 37).

Se a ontogênese náo repete a filogênese, como estudar o desenvolvimento cultural infantil e dos adultos considerando, com Vigotski, que há evolução, involução e revolução nesses desenvolvimentos?

Para Vigotski, sem a definição de um método que possibilite a compreensão do especificamente humano, não há como entender esses desenvolvimentos, pois, para ele, "o problema do método é o princípio e a base, o alfa e o ômega de toda a história cultural das crianças" (VIGOTSKI, 1995, p. 47) e de todo o ser humano. Para esse autor, o método histórico e dialético é o que melhor poderá contribuir para se estudar o desenvolvimento humano, que se pauta pela compreensão da formação das funçóes psíquicas superiores, que são funçóes de origem cultural e especificamente humanas. O estudo histórico dessas funçōes significa aplicar as categorias do desenvolvimento à investigação dos fenômenos, pois estudar algo historicamente significa estudá-lo em movimento. Esta é a exigência do método dialético. Quando, em uma investigação, leva-se em conta o processo de desenvolvimento de algum fenômeno, em todas as suas fases e transformaçóes/mudanças, desde que surgiu até o seu desaparecimento, isso implica colocar em evidência sua natureza, conhecer sua essência, já que só em movimento um corpo demonstra que existe. Assim, a investigação histórica do desenvolvimento das funçóes superiores de crianças e adultos não é algo que complementa ou ajuda o estudo teórico, senão que constitui o seu fundamento. Assim, esse desenvolvimento só pode ser compreendido como história do desenvolvimento. (VIGOTSKI, 1995, p. 67-68). 
Sob essa perspectiva, em nossa pesquisa na sala de aula de EJA, há que se pautar pela história do desenvolvimento dos estudantes acerca da apropriaçáo do conceito de fraçôes e de frações equivalentes. Há que se perguntar: o que aconteceu e o que se desenvolveu ali? Há que se desvelar as culturas das duas salas de aulas onde fizemos a pesquisa. Quais foram as vivências que possibilitaram oportunidades de desenvolvimento, de transformaçóes das pessoas, na compreensão do conceito de fraçóes?

Entendemos que são as vivências que possibilitam a construção e adaptação, ao mesmo tempo, de objetivos concretos, capacidades, conhecimentos. São possibilidades relacionadas à zona de desenvolvimento iminente a serem alcançadas e apreendidas pelas pessoas, que "passam a ser seu patrimônio, sua experiência de vida acumulada, entretanto, essa zona é inatingível como a linha do horizonte" (JERESBTSOV, 2014, p. 20), pois está em constante transformação. Cria condiçóes para a construção da personalidade não como um arquivo, mas "por meio da reconstrução, por meio da morte do antigo [...] vale recorrer ao sentido literal da palavra pere-jivat", ou seja, "passar por meio da vida, estar em caminho permanente, em busca, sempre morrer e nascer, estar em processo de reformulação de si mesmo, no fluxo da vida, levando o desenvolvimento da personalidade a uma posição existencial de tensão, de drama”, como dizia Vigotski (2000, p. 21).

$\mathrm{E}$ isso só acontece porque desenvolvemos a capacidade de mediação semiótica por meio do uso de diferentes signos culturais. Segundo Vigotski, há um duplo nascimento: o biológico e o cultural; as crianças precisam reconstituir nelas mesmas e não somente reproduzir o que já foi conquista da humanidade. A natureza humana é a síntese entre natureza e cultura. Nessa síntese, nos tornamos humanizados, podemos lidar com signos variados e mutáveis, produzindo significação para o mundo à nossa volta por meio do sistema de significados que produz a unidade entre pensamento e fala. Então, a significação (que envolve sentido e significado) é o que permite articular o agir, o sentir e o pensar. Essa perspectiva articula pensamento e fala como uma unidade de análise do desenvolvimento humano.

Segundo Bakhtin (1992), a palavra só adquire sentido no contexto da interlocução, entre múltiplas e variadas vozes. Nesse sentido, produzimos o discurso, que é sempre polissêmico, polifônico, ideológico. Não há transparência no discurso, mas opacidade, escondem-se e revelam-se coisas ao se dizer algo, para alguém. Assim, "o discurso é um processo de produção social de significação e a língua um instrumento dessa produção.” (PINO,1991, p. 39).

Dessa forma, a mediação semiótica não se reduz ao campo da fala, das palavras, mas implica as ações e interações, as imagens, os sentimentos, o 
real, o imaginário e o simbólico. O que nos permite compreender o processo de constituiçáo do humano como um processo histórico, social, como um "processo permanente de produção" (PINO, 1991, p. 42) do indivíduo social. Indivíduo social é um conceito que nos revela a natureza semiótica das atividades psíquicas que nos permitem simbolizar, imaginar, sentir, pensar, falar e produzir sentidos para a nossa existência e para o mundo em que vivemos. Permite-nos refletir, com Vigotski, que, para se entender esse processo, há que se substituir o método de estudo atomístico, de estudo de elementos, pelo método da unidade, entendendo por unidade "o resultado da análise, que diferentemente dos elementos, carrega todas as propriedades fundamentais características do conjunto e constitui uma parte viva e indivisível da totalidade." (VIGOTSKI, 1993, p. 19).

Seguindo esse raciocínio, trazemos as contribuiçóes da Etnografia em Educação (SBCDG, 1992; GREEN; DIXON; ZAHARLIC, 2005), que postula a centralidade do diálogo com os participantes da pesquisa, nas perspectivas êmica e ética. Há que se produzir o material empírico com base nos pontos de vista desses participantes, há que se fazer uma descrição densa do que acontece nas práticas culturais, combinada com a análise e a interpretação. Há que estudar os padróes culturais das salas de aulas por meio da perspectiva etnográfica, guiando-se pela análise do discurso (BAKHTIN, 2003), considerando os conceitos Bakhtianos: cronotopo e exotopia.

Para Bakhtin (2003), o cronotopo é a porta de entrada da análise do gênero, isso é, o centro de organização dos acontecimentos espaço-temporais (eventos da sala de aula). Um novo cronotopo significa nova forma de comunicação, novas formas de linguagens, novos gêneros, novos sentidos, novos conteúdos e novas relações sociais, que podem adquirir caráter fantástico, mágico (BEZERRIL; PEREIRA, 2011) e, também, ficcional, científico, escolar, político, religioso, ideológico. Essas novas relaçóes, novos sentidos, acontecem porque o cronotopo é dialógico.

Nesse processo de dialogia, acontece a exotopia, pois

[...] quando contemplamos o outro, nossos horizontes concretos vivenciáveis não coincidem, isto é, enquanto sujeito singular e insubstituível ao contemplar um homem situado fora e diante de mim, nossas visóes de e do mundo não são coincidentes [...] Em qualquer situação de proximidade que este outro esteja em relação a mim, sempre verei e saberei algo que ele, da sua posiçáo fora e diante de mim não pode ver. (BAKHTIN, 2003, p. 21). 
Por isso, há que se quebrar o círculo em torno da lingua, e conectá-la com a cultura, modificando nossa visão sobre o mundo. A linguagem é que cria a cultura, mas a cultura também cria linguagem, fazendo o caminho para a construção de múltiplas identidades que se modificam a qualquer tempo (AGAR, 2002). Agar aponta algo muito importante na análise do discurso: os Rich Points, que são, em tradução livre, os pontos relevantes da languaculture (línguacultura). Entretanto, nem sempre é fácil entender o que o outro diz, como diz e quais são as referências contextuais nas quais se apoia. Daí, vem a nossa preocupação em compreender os sistemas de significados que as pessoas produzem sobre as açóes e eventos de que participam. Esses sistemas de significados constituem sua cultura; etnografia sempre implica uma teoria da cultura (SPRADLEY, 1980, p. 5).

Para desenvolver nossas pesquisas nas salas de aulas, tendo como base as perspectivas já apresentadas, fazemos uso da observação participante, da anotação em cadernos de campo, da gravação de vídeo e áudio, de fotos, entrevistas semiestruturadas e conversas informais com os participantes da pesquisa. O material empírico produzido nós o representamos em Mapas de Eventos e Sequências Discursivas, que nos permitem construir a lógica de investigação desse estudo.

\section{Lógica de investigação na sala da EJA}

Para ilustrar nossa forma de desenvolver pesquisas nas salas de aula, apresentamos aqui uma investigação conduzida por Araújo (2017) em duas turmas de EJA do segundo segmento do Ensino Fundamental. O objetivo desse trabalho era compreender como os jovens e adultos em processo de escolarização apropriam-se de conceitos da matemática escolar. O material empírico foi produzido pela observação-participante nas aulas de matemática durante um ano e colocou em contraste os processos de apropriação ocorridos em duas turmas, revelando a relação entre instrução escolar e desenvolvimento de adultos.

Segundo Prestes (2010, p. 188), a instrução (obutchenie, em russo) envolve "a atividade da criança, a orientação da pessoa e a intençấo dessa pessoa." Portanto, ao voltar o olhar sobre a instrução, Vigotski lança luzes também sobre o processo de autoinstrução dos estudantes que ocorre em sala de aula. Não sobre o que os estudantes já sabem fazer, mas sobre o desenvolvimento provocado pela instrução. Assim, diferentemente do que muitos autores afirmam (que Vigotski estabeleceu uma relação entre aprendizagem e desenvolvimento), estabelece-se 
uma relação entre instrução e desenvolvimento. E a instrução, junto com a autoinstruçáo, pode ser considerada como a atividade guia do desenvolvimento mental e cultural, tal qual descrita por Vigotski, como aquela que afeta os estudantes, que os mobiliza a ir ao encontro da compreensão dos conteúdos escolares. Assim, a tradução da palavra obutchenie por aprendizagem modifica de maneira profunda, como alerta Prestes, o próprio entendimento da teoria de Vigotski. Embora essa teoria tenha sido desenvolvida para compreensão do desenvolvimento infantil, consideramos que pode ser redimensionada para o desenvolvimento de adultos em processo de escolarização, como as pessoas participantes da pesquisa que aqui descrevemos.

Ao focar a relação entre instrução e desenvolvimento, buscou-se compreender a cognição de adultos que se apropriam de determinados conceitos de matemática, olhando para um processo, para algo que está acontecendo e que, por isso, náo pode ser compreendido fora do fluxo dos acontecimentos na sala de aula. Não havia uma hipótese inicial delimitada para esse trabalho, mas sim o desejo de contrapor um discurso que coloca o aluno a e aluna da EJA como pessoas com dificuldade para aprender. Portanto, a lógica de investigação desta pesquisa começou a ser construída na escolha por fazer uma etnografia da sala de aula. A forma de indicar a organização da análise, mostrada no quadro a seguir, foi elaborada com base nos trabalhos de Castanheira et al. (2001), Gomes, Dias e Vargas (2017) e Dias (2015). 
Quadro 1 - Representação da lógica de investigação em uso na pesquisa

Propondo questões analíticas: 0 que foi ensinado nas aulas de matemática durante 0 ano?

Representando dos dados: Elaboração de quadros com a descrição dos conteúdos ensinados em cada turma, principais atividades desenvolvidas e a organização das turmas.

Analisando os dados: $\mathrm{A}$ partir da visão panorâmica das aulas de matemática que aconteceramnaquele ano, construir análises considerando sua distribuição, o tempo gasto com cada tema, os recursos usados pela professora, utilizando as anotações do caderno de campo para destacar momentos que pareceram importantes tendo emvista a questão geral de pesquisa, identificando possiveis conteúdos cujas aulas poderiam ser focalizadas nas análises posteriores.

Propondo questões analíticas: Quais foram os principais conœitos estudados nessas aulas? Como as aulasforam organizadas tendo emvista a construção desses conceitos?


realizado emtodas as aulas referentes ao conteúdo escolhido, com destaque para o conceito principal estudado em cada uma delas.

Analisando os dados: Análise da descrição detalhada das aulas, das gravacoúes em vídeo e anotações do caderno de campo para selecionar uma sequência de aulas, preferencialmente, sobre o mesmo conœito, procurando identificar aquelas em que as "dificuldades" eram expressas por alunos e professoracom mais ênfase.

Propondo questões analiticas: Quaisforam os eventos nas aulas escolhidas nos quais as interações discursivas revelamindicios sobre os processos de apropriação dos alunos?

Representando os dados: Construção dos mapas de eventos das aulas escolhidas.

Analisando os eventos: Levantamento dos eventos nos quais os alunos fazem perguntas, comentários, explicações sobre o conceito a ser apropriado por e les.

Propondo questões analíticas: Quais são os alunos que perguntam, comentam ou explicam ace rca do conce ito? $O$ que eles dizem? Para quem? Com que consequência? Repetem um padrão de participação observado durante $o$ ano? Quem não diz nada? Qualé a movimentação dos alunos nessas aulas? Que conversas "parale las" ocorrem?

Representando os dados: Transcrição das aulas escolhidas para a análise . Analisando os eventos: Análise das interações discursivas.

Fonte: Araújo (2017). 
Esse esquema mostra qual foi o percurso etnográfico seguido, até culminar na análise microgenética, produzida ao final desse caminho. Na primeira etapa da análise, procurou-se construir um panorama das aulas de matemática daquelas turmas, naquele ano. Com esse mapeamento, foram identificados os conceitos estudados ao longo do ano, de modo a selecionar as sequências de aulas que se mostrassem, pelo modo de participaçáo dos alunos, potencialmente relevantes para a compreensão dos processos de apropriação dos alunos e das alunas das duas turmas.

Para essas aulas, foram produzidos mapas de eventos para explicitar o que ocorria em cada uma delas. Numa primeira organização, os eventos constituíramse de fases da aula claramente marcadas por uma mudança na organização da turma, no tipo de interação ou nos objetivos pretendidos pela professora. Cada um deles envolvia uma intencionalidade e promove certos modos de engajamento. O tempo gasto com cada um desses eventos foi registrado nos mapas, pois essa informação poderia dar pistas sobre a importância e o significado para as pessoas, dos eventos analisados.

Nesses mapas, as aulas foram descritas e contextualizadas, de modo a fornecer elementos para que a análise não fosse episódica e pudesse oferecer uma compreensão mais ampla de cada evento, na medida em que ele se relaciona com os demais que o antecederam, em aulas anteriores. Foram registradas informaçóes sobre a movimentação na sala de aula (quem chega, quem sai, quem se levanta para ir à mesa do colega, a posição em que a professora está), a organização do espaço (posição das carteiras), dentre outras; e, ainda, informaçóes sobre outras aulas, que pudessem ajudar a compreender a dinâmica dos eventos ali construída.

Com essa forma de organizar e analisar as aulas - os mapas de eventos -, podese perceber que "qualquer evento é historicamente influenciado pelos eventos que o precedem, naquele dia ou em dias anteriores." (GOMES, 2004, p. 67). Os mapas revelaram como as pessoas (alunos, alunas e professora) participam da aula: quem fala, o que fala, para quem e com que consequência; como os alunos, por meio de perguntas e observaçóes, mudam os rumos da aula e modificam as possibilidades de desenvolvimento. Isso tornou possível ultrapassar a análise do conteúdo das falas e fazer uma análise do discurso.

Continuando o processo de focalização, a partir desses mapas, foram eleitos os eventos cujas interaçóes discursivas pudessem fornecer indícios sobre os processos de apropriaçáo dos conceitos matemáticos pelos alunos. Nesses eventos, foram identificadas as sequências discursivas que poderiam ser reveladoras dos processos que se desejava analisar. Essas sequências foram, então, transcritas para a análise.

O longo tempo de observação é que possibilita todo esse percurso de focalização, de modo que o que se diz e o que se faz, durante cada Sequência 
discursiva selecionada, constituam-se como uma unidade de análise que não se dissocia de todo o conjunto de aulas observadas e das pessoas que constituem aquela sala de aula.

\section{Adentrando a sala de aula da EJA}

Para compreender o processo de apropriação de conceitos matemáticos por jovens e adultos alunos da EJA, voltamos nosso olhar sobre o material empírico, com algumas questóes tomadas como ponto de partida. Algumas delas já consideravam o conceito de vivência cunhado por Vigotski e que se tornaria chave em nossa análise: de que maneira as vivências dos alunos e das alunas contribuíam no processo de apropriação dos conceitos estudados? As vivências dessas pessoas confrontam os conceitos escolares, objeto de estudo daquelas aulas? Se sim, de que maneira? De que forma o concreto e o abstrato estáo presentes nesses processos de apropriação?

Neste artigo, apresentamos primeiramente a análise de um evento ocorrido em uma das duas turmas pesquisadas, a turma 81 . Nessa aula, a professora tinha a intenção de introduzir o conceito de fração equivalente e, para isso, usou o texto de um livro didático escrito para estudantes da EJA. A história do empreendimento de Miralva foi o ponto de partida para a construção desse conceito. Na história, Miralva decide fazer torta de frango para vender na porta de uma escola e ganhar dinheiro para pagar suas despesas. Ela usou uma assadeira redonda e dividiu a torta em 8 fatias. Com esse pretexto, apresenta-se o conceito de fração. Cada fatia da torta corresponde a $1 / 8$ (um oitavo) da torta. Cada pedaço seria vendido por $\mathrm{R} \$ 3,00$. Miralva conseguiu vender, certo dia, 3/8 da torta. "Vendeu tão pouco, coitada", foi o comentário de uma aluna, já atribuindo significado à fração $3 / 8$ (três oitavos) no contexto proposto. Afinal, vender menos da metade da torta não é realmente animador.

Mais adiante, o livro mostra que a situação mudou quando Miralva decidiu dividir a torta em 16 pedaços, ao invés de 8 , para alavancar as vendas. A ideia era mostrar que, para ganhar a mesma quantia que havia conseguido, ela precisaria vender $6 / 16$ (seis dezesseis avos) da torta, concluindo, com isso, que a fração $3 / 8$ é equivalente à fração $6 / 16$. Nessa aula, após a leitura do livro, a professora perguntou quanto seria o preço da nova fatia. Éder, um dos alunos da turma, rapidamente respondeu que, se antes a fatia custava três reais, agora passaria a custar "um e cinquenta". Essa resposta, porém, não satisfez a todos na turma, como revela a Sequência discursiva apresentada no Quadro 2, a seguir: 
Quadro 2 - Sequência discursiva - "Não vai adiantar nada" - Aula de 03/09/15 - Turma 81

\begin{tabular}{|c|c|c|}
\hline \multicolumn{3}{|c|}{ Tempo de gravação: de 47:10 a 48:00 (duração: 50 s) } \\
\hline Linha & Unidade de Mensagem & Contextualização \\
\hline 878 & $\begin{array}{l}\text { Jackson: Mais ela pode cobrar dois reais de cada } \\
\text { pedaço/ }\end{array}$ & \multirow{2}{*}{$\begin{array}{l}\text { O pedaço mencionado por Jackson } \\
\text { corresponde a } 1 / 16 \text { da torta. }\end{array}$} \\
\hline 879 & $\begin{array}{l}\text { que ela vai lucrar / ganhar mais que vinte e } \\
\text { quatro/ }\end{array}$ & \\
\hline 880 & Teresinha: é:..:/ é isso que eu não tô entendendo/ & \multirow{2}{*}{$\begin{array}{l}\text { Teresinha está sentada na frente, } \\
\text { bem próxima ao quadro. }\end{array}$} \\
\hline 881 & Prof.: ok? & \\
\hline 882 & Teresinha: Por que ela aumentou só:...: & \\
\hline 883 & Warley: Então não vai adiantar nada. & \multirow{2}{*}{$\begin{array}{l}\text { Warley e Éder estão sentados no } \\
\text { fundo da sala. }\end{array}$} \\
\hline 884 & Prof.: Mas assim/ & \\
\hline 885 & Teresinha: Menos ... & \\
\hline 886 & $\begin{array}{l}\text { Prof.: Eu:.:/ eu:/ não::/ na verdade / a torta } \\
\text { continua no mesmo tamanho / }\end{array}$ & \\
\hline 887 & $\begin{array}{l}\text { então o custo que ela tem / pra fazer/ continua o } \\
\text { mesmo/ }\end{array}$ & \\
\hline 888 & Teresinha: Hã. & \\
\hline 889 & $\begin{array}{l}\text { Prof.: Que a torta é do mesmo tamanho/ o que } \\
\text { diminuiu foi tamanho / da fa::tia / }\end{array}$ & \\
\hline 890 & $\begin{array}{l}\text { porque antes ela dividia em oito pedaços / agora } \\
\text { ela vai dividir em/ em dezesseis/ }\end{array}$ & \\
\hline 891 & $\begin{array}{l}\text { Mas é do mesmo tama::nho / a fôr::ma/ a fôrma } \\
\text { que ela tem }\end{array}$ & \\
\hline 892 & Teresinha: A mesma? & \\
\hline 893 & Prof.: A torta é a mesma. & \\
\hline 894 & Teresinha: Mas ela vendendo a um e cinquenta ... & \\
\hline 895 & Prof.: Ela vai lucrar os mesmo vinte e quatro. & 24 reais \\
\hline 896 & $\begin{array}{l}\text { Teresinha: Pois então?/ é isso que eu quero } \\
\text { entender. }\end{array}$ & \\
\hline 897 & Jackson: Ela não precisa aumentar o lucro, não. & \\
\hline 898 & $\begin{array}{l}\text { Teresinha: Assim é se fosse para uma festa/ ela ia } \\
\text { pensar/ nossa senhora/ é muita gente/ }\end{array}$ & \\
\hline
\end{tabular}

Fonte: Gravação das aulas 
Jackson sugeriu que o preço da fatia fosse de 2 reais. Nesse momento, vemos em cena uma solução mais escolar (se dividiu a fatia por 2 , o preço se dividiu por 2 também), que serviu como exemplo para o estudo das fraçôes equivalentes; e uma solução mais focada nas demandas da vida real, de quem vende torta de frango e precisa ganhar dinheiro com isso. Não foi surpreendente, portanto, que a resposta escolar causasse certo estranhamento, levando-se em conta que o trabalho informal havia sido mencionado em muitas entrevistas com alunos e, principalmente, alunas da turma.

A solução de Miralva para o seu problema não pareceu adequada para Teresinha e Warley. Os sentidos atribuídos foram de algo inútil, já que vendendo $6 / 16$ da torta, nessa nova situação, em que cada fatia custasse $R \$ 1,50$, ela lucraria os mesmos 9 reais de quando havia vendido $3 / 8$ da torta e ainda teria de conseguir o dobro de compradores. Mesmo Jackson, um aluno com bastante traquejo com a matemática escolar, sugeriu que a fatia fosse vendida por dois reais, mostrando que, para ele, naquele momento, não se tratava de um problema estritamente matemático, envolvendo proporcionalidade. $\mathrm{O}$ problema era a situação de Miralva, que precisava ganhar dinheiro e não poderia fazer a torta para vender e voltar para casa com mais da metade. Para Teresinha, partir a torta em fatias menores faria sentido se fosse para distribuir para muita gente: "se fosse para uma festa" (linha 898), mas não para vender e continuar tendo o mesmo lucro máximo, 24 reais. Assim como Miralva, Teresinha também já dependera do trabalho informal, como ela contou em sua entrevista.

Quadro 3 - Entrevista com Teresinha (turma 81) - "trabalhei por conta própria"

Contextualização: Nesse ponto da conversa, Teresinha acabara de contar que trabalhava com o pai, como corretora, antes de se casar, e a pesquisadora pergunta se ela continuou a trabalhar fora depois do casamento.

\begin{tabular}{|c|l|}
\hline Linha & \multicolumn{1}{c|}{ Unidade de mensagem } \\
\hline 093 & Aí::/ virei dona de ca::sa/mai:.:s/ teve/ aquele/ né/ o marido não ganhava/ \\
\hline 094 & TÃo bem na assinada/ tive de ganhar/ então eu vendi roupa/ muitos anos/ \\
\hline 095 & depois vendi coisa do Paraguai/ então/ sempre fazendo alguma coisinha para ajudar/ \\
\hline 096 & manter a casa/ né/ então/ foi (...)/eu trabalhei assim/ trabalhei por conta própria \\
\hline
\end{tabular}


O trabalho informal que Teresinha realizava não era apenas um complemento à renda familiar, mas era necessário para "ajudar/ manter a casa" (linhas 95 e 96). Talvez, por ter vivenciado as incertezas desse tipo trabalho, sem vínculo empregatício, ela tenha sido afetada pelo fracasso da personagem Miralva com sua venda de tortas. Essa impressão pode ter feito Teresinha olhar para a situação de Miralva do ponto de vista da necessidade de ganhar dinheiro e náo do ponto de vista da lógica matemática, em que a venda de tortas era apenas um pretexto para o ensino de fraçáo equivalente, que poderia ser substituído por outra história. O questionamento de Teresinha constituiu-se, entáo, como um ponto relevante que, como explica Agar (2002), trouxe consequências significativas para os participantes daquele grupo, confrontando o que, naquele momento, contava como conhecimento escolar naquela sala de aula.

A partir desse momento, vários alunos participaram da Sequência discursiva para construir um sentido útil para a ação de Miralva. Ao trazer uma situação supostamente da vida cotidiana para o ensino da matemática, o cotidiano foi moldado para servir ao conceito de matemática que se queria construir. A proporção entre preço e quantidade nem sempre é a da prática, na vida cotidiana. Por exemplo, quando uma fábrica de biscoitos resolve criar uma embalagem menor (com menos gramas de biscoito), quase sempre, o preço não fica proporcionalmente menor, mas fica apenas menor. Isso, algumas vezes, pode iludir o consumidor, que, se náo fizer os cálculos adequados, pode achar que está economizando, quando, na verdade, não está. O que Miralva precisaria, do ponto de vista dos alunos da turma, era garantir o lucro ou, pelo menos, evitar o prejuízo.

Ao dizer "então não vai adiantar nada" (linha 881), Warley lançou dúvidas sobre a eficiência desse procedimento para o objetivo de vender mais, de ganhar mais dinheiro. Ganhar dinheiro com o trabalho informal é bem mais complexo do que a matemática escolar quer fazer parecer. Diante disso, os próprios alunos tentaram salvar a situação, buscando construir algum sentido para a solução de Miralva para vender mais tortas, como se pode ver na Sequência discursiva do quadro 4: 
Quadro 4 - Sequência discursiva - "Tem pessoas que comem pouco" - Aula de 03/09/15 - Turma 81

\begin{tabular}{|c|c|c|}
\hline \multicolumn{3}{|c|}{ Tempo de gravação: de 48:03 a 49:06 (duração: $1 \mathrm{~min} 3 \mathrm{~s}$ ) } \\
\hline Linha & Unidade de Mensagem & Contextualização \\
\hline 902 & Warley: Tem pessoas que comem pouco/ né? & \multirow{3}{*}{$\begin{array}{l}\text { Warley faz um gesto com as mãos para } \\
\text { mostrar uma quantia pequena. }\end{array}$} \\
\hline 903 & Jackson: Mas se ela ser::vir/ & \\
\hline 904 & $\begin{array}{l}\text { Pesq.: É que um pedaço grande/ tem gente } \\
\text { que desanima de comprar. }\end{array}$ & \\
\hline 905 & Alguém: É:::: & \\
\hline 906 & $\begin{array}{l}\text { Éder: Heim, Jackson? / mas aí ela não vai } \\
\text { vender/ }\end{array}$ & \multirow{2}{*}{$\begin{array}{l}\text { Éder está no fundo da sala e Jackson } \\
\text { próximo ao quadro. }\end{array}$} \\
\hline 907 & só / três pedaço/ ela ia vender tudo & \\
\hline 908 & Teresinha: É:: & \\
\hline 909 & Éder: Vai ter lucro & \\
\hline 910 & $\begin{array}{l}\text { Teresinha: Aí ela não tá olhando a quantidade } \\
\text { de lucro/ tá olhando ... }\end{array}$ & \\
\hline 911 & Prof.: É pelo seguinte... & \\
\hline 912 & Warley: Aí ela ganha dinheiro. & \\
\hline 913 & Prof.: Deixa o Jackson falar & \multirow{3}{*}{$\begin{array}{l}\text { Jackson estava com a mão levantada, } \\
\text { solicitando a oportunidade de falar. }\end{array}$} \\
\hline 914 & $\begin{array}{l}\text { Warley: Aí atrai os clientes/ por causa do } \\
\text { preço, }\end{array}$ & \\
\hline 915 & (Teresinha) Ai ai::: & \\
\hline 916 & Prof.: Deixa o Jackson falar/ vai. & \\
\hline 917 & $\begin{array}{l}\text { Jackson: Se ela dividir a torta em oito/ } \\
\text { pedaços/ }\end{array}$ & \\
\hline 918 & oito oitavos/ da torta/ tava deixando & \multirow{4}{*}{$\begin{array}{l}\text { A professora dá a Jackson a tarefa de } \\
\text { fazer uma síntese da discussão. Os } \\
\text { colegas ouvem Jackson com atenção. }\end{array}$} \\
\hline 919 & $\begin{array}{l}\text { metade da torta/ficando no pra::to/ das } \\
\text { pessoas. }\end{array}$ & \\
\hline 920 & Teresinha: Entendi. & \\
\hline 921 & $\begin{array}{l}\text { Jackson: Ela pensou/Não/ então eu posso } \\
\text { vender um pedaço menor/ }\end{array}$ & \\
\hline
\end{tabular}




\begin{tabular}{|c|c|c|}
\hline \multicolumn{3}{|c|}{ Tempo de gravação: de 48:03 a 49:06 (duração: 1 min3s) } \\
\hline Linha & Unidade de Mensagem & Contextualização \\
\hline 922 & $\begin{array}{l}\text { porque/ vou ter mais tortas pra ser::vir pro } \\
\text { pessoal/ }\end{array}$ & \\
\hline 923 & que aí vai ter mais fati::as. & \\
\hline 924 & Teresinha: Isso/ tem duas (bocadas) a mais. & \\
\hline 925 & $\begin{array}{l}\text { Jackson: Então/ eu vou por:: um preço/ pra } \\
\text { lucrar os vinte e quatro reais. }\end{array}$ & \\
\hline 926 & Prof.: É:: & \\
\hline 927 & Teresinha: Ela quer lucrar tudo. & \\
\hline 928 & Warley: Eu já trabalhei::/ na:::// & \\
\hline 929 & Prof.: Ela quer lucrar os vinte e quatro. & \multirow{7}{*}{$\begin{array}{l}\text { Savassi é um bairro, em Belo Horizonte, } \\
\text { de classe média alta, conhecido pelo } \\
\text { comércio e imóveis bem valorizados. } \\
\text { Warley fecha os dedos para indicar o } \\
\text { tamanho minúsculo da fatia. }\end{array}$} \\
\hline 930 & Warley: Eu trabalhei em padaria/ né?/ & \\
\hline 931 & lá na Savassi/ e lá o pessoal pega come/ coisa/ & \\
\hline 932 & $\begin{array}{l}\text { bem pequeni::ninha:: assim/ coisa que pra } \\
\text { mim::/ }\end{array}$ & \\
\hline 933 & não sei (riso)/ mas pra eles:.:/ & \\
\hline 934 & Se a gente cortasse/pedaço grande/ & \\
\hline 935 & $\begin{array}{l}\text { eles não levava/ eles queriam coisa/ bem } \\
\text { pequena }\end{array}$ & \\
\hline
\end{tabular}

Fonte: Gravação das aulas

Ao dizer que "têm pessoas que comem pouco" (linha 902), Warley iniciou uma construção de sentido com seus colegas. Ele reforçou a ideia de que a fatia menor pode ser mais atrativa para um determinado público consumidor (classe média alta), trazendo sua vivência de já ter trabalhado em uma padaria de um bairro considerado nobre, em Belo Horizonte. Warley também apontou o preço menor como um atrativo para as vendas: "Atrai os clientes, por causa do preço" (linha 914), ele disse. Ainda que o total possível de ser arrecadado continuasse o mesmo (24 reais), nessa situação, segundo Éder, "ela não vai vender /só / três pedaços/ ela ia vender tudo" (linha 906 e 907). Jackson fez uma síntese da explicação construída pelo grupo, que foi aceita por Teresinha, que colocara em dúvida a lógica daquela situação, mostrando um descolamento da centralidade da professora nas explicaçóes sobre os conceitos estudados.

Um dos pressupostos da Etnografia em Educação é a análise contrastiva. No caso desta pesquisa, duas turmas, que iniciavam o segundo segmento fundamental, com a mesma professora, fazendo as mesmas atividades, foram 
colocadas em contraste. Isso não significa que foi realizada uma mera comparação entre as turmas. Ao serem postas em contraste, revelaram-se as singularidades dos processos de apropriação dos conceitos matemáticos, em cada turma.

A seguir, o Quadro 5 apresenta, lado a lado, sequências discursivas das duas turmas. A análise dessas sequências mostrou que existiram mudanças nos enunciados da professora, ao desenvolver a mesma atividade nas duas turmas. Nessa aula indicada no quadro, por exemplo, a professora leu, nas duas turmas, o trecho do livro que explica as razóes pelas quais Miralva resolveu diminuir o tamanho da fatia da torta que ela vendia, enfatizando que "as fatias estavam grandes e caras para um lanche". Nesse momento, a professora já havia desenhado um círculo dividido em oito partes iguais para representar a primeira situação da torta de Miralva. Ela dividiu, então, no desenho, cada parte (fatia) em duas, para que o círculo ficasse fracionado em 16 partes. A partir daí, a instrução, nas duas turmas, se diferenciou, como vemos nas sequências discursivas no quadro a seguir.

\section{Quadro 5 - Contraste das aulas do dia 03 de setembro - primeiro trecho}

\begin{tabular}{|c|l|c|l|}
\hline \multicolumn{2}{|c|}{$\begin{array}{c}\text { Aula do dia 03/09/15 - Turma 81 } \\
\text { Tempo de gravação: de 45:27 a 46:27 } \\
\text { (duração: 1min) }\end{array}$} & \multicolumn{2}{c|}{$\begin{array}{r}\text { Aula do dia 03/09/15 - Turma 80 } \\
\text { Tempo de gravação: de 32:31 a 33:31 } \\
\text { (duraça: 1min) }\end{array}$} \\
\hline Linha & \multicolumn{1}{|c|}{ Unidade de Mensagem } & Linha & \multicolumn{1}{c|}{ Unidade de mensagem } \\
\hline 841 & Prof.: Então ela dividiu aqui de novo. & 602 & $\begin{array}{l}\text { Prof.: Então o que ela fez/ ela } \\
\text { dividiu a torta agora/ }\end{array}$ \\
\hline 842 & Jackson: Ó.:.: & 603 & em dezesseis pedaços/ tá?/ \\
\hline 843 & Éder: E ela abaixou o preço? & 604 & $\begin{array}{l}\text { dezesseis/dividiu em dezesseis } \\
\text { pedaços/ }\end{array}$ \\
\hline 844 & Jackson: É:./ tem que saber isso (risos). & 605 & $\begin{array}{l}\text { pra ela dividir em dezesseis } \\
\text { pedaços/ o que ela fez?/ }\end{array}$ \\
\hline 845 & Prof.: Será? & 606 & .../comparando com a torta/ \\
\hline 846 & $\begin{array}{l}\text { Pesq.: Ah:.: /capaz que não/ ela quer } \\
\text { é ganhar. }\end{array}$ & 607 & $\begin{array}{l}\text { que era dividida em oito } \\
\text { pedaços/ o quê que foi feito } \\
\text { aí? }\end{array}$ \\
\hline 848 & Weresinha:( inaudível) & 608 & $\begin{array}{l}\text { Walter: Diminuiu os pedaços } \\
\text { (inaudível) }\end{array}$ \\
\hline 849 & Warley: Inteira/ seria ... & 609 & Prof.: É/ diminuiu o tamanho/ \\
\hline
\end{tabular}




\begin{tabular}{|c|l|c|l|}
\hline \multicolumn{2}{|c|}{$\begin{array}{c}\text { Aula do dia 03/09/15 - Turma 81 } \\
\text { Tempo de gravação: de 45:27 a 46:27 } \\
\text { (duração: 1min) }\end{array}$} & \multicolumn{2}{c|}{$\begin{array}{c}\text { Aula do dia 03/09/15 - Turma 80 } \\
\text { Tempo de gravação: de 32:31 a 33:31 } \\
\text { (duração: 1min) }\end{array}$} \\
\hline Linha & \multicolumn{1}{|c|}{ Unidade de Mensagem } & Linha & \multicolumn{1}{c|}{ Unidade de mensagem } \\
\hline 850 & Jackson: Vinte e quarto. & 611 & $\begin{array}{l}\text { em dois pedaços/ E aí/ agora } \\
\text { ela tem/ dezesseis pedaços/ }\end{array}$ \\
\hline 851 & Prof.: É/ então vamos pensar. & 612 & $\begin{array}{l}\text { certo?/então / agora ela tem } \\
\text { dezesseis/ }\end{array}$ \\
\hline 852 & Warley: Como que é... & 613 & qual que é a fração que \\
\hline 854 & Prof.: Se/se uma torta toda... & 614 & $\begin{array}{l}\text { corresponde a uma fatia/ aqui } \\
\text { agora? }\end{array}$ \\
\hline & Warley: Um e cinquenta... & 615 & $\begin{array}{l}\text { João Carlos: Um se:.:is/ um } \\
\text { se::is/dezesseis... }\end{array}$ \\
\hline & & 616 & Walter: ...avos. \\
\hline & & 617 & $\begin{array}{l}\text { José Geraldo: Dezesseis avos. } \\
\text { Certo?/ Uma fatia aqui agora } \\
\text { corresponde a um dezesseis } \\
\text { avos/. }\end{array}$ \\
\hline
\end{tabular}

Fonte: Gravação das aulas

Na aula da turma 81, que antecedeu a da turma 80, a preocupação com o novo preço da fatia apareceu logo que a torta foi redividida, quando Éder perguntou: "e ela abaixou o preço?" (linha 843), e Warley logo se adiantou para dar a resposta: "um e cinquenta" (linha 854). Nessa turma, as interaçóes verbais aconteceram mais entre os estudantes, que direcionaram suas compreensóes para mais um capítulo da história de Miralva, o que os levou a conversar sobre a situação da mulher na sociedade. Isso fez com que os alunos reconhecessem e lamentassem o fracasso das vendas de Miralva, de modo que eles mantivessem o foco no desfecho da história, na resoluçáo do problema das vendas de Miralva. O que orientou os encaminhamentos da professora parece ter sido a história desse evento, o modo como ele foi construído em aulas anteriores e a forma de participação dos alunos.

A turma 80 não constituiu o mesmo vínculo com a história de Miralva. Pensamos que isso se explique, em parte, porque a professora falava mais, direcionava mais do que na turma 81 , de modo que as falas dos alunos eram respostas às perguntas avaliativas da professora. $\mathrm{O}$ foco das falas da professora não foi, a princípio, o novo preço da fatia, mas a fração que correspondia à nova fatia, $1 / 16$. 


\section{Considerações finais}

Estabelecendo diálogo entre a Psicologia Histórico-cultural e a Etnografia em Educação, a pesquisa aqui apresentada buscou compreender como se dá o processo de apropriação dos conceitos matemáticos por jovens e adultos no Ensino Fundamental da EJA. A tese era de que se trata de processos complexos, que só se explicam pela constituição cultural das salas de aula e das pessoas: professora, alunas e alunos das turmas pesquisadas. Com isso, pretendia-se evidenciar a relaçáo entre instrução escolar e desenvolvimento de adultos, sem buscar referências, tampouco comparações, com o ensino para crianças e adolescentes.

A história do empreendimento de Miralva, ponto inicial para a introdução do conceito de fração equivalente, foi lembrada em todas as outras aulas, como referência, sempre que a professora desejava voltar à definição construída por meio daquela história. Na turma 81 , a história, desde a sua primeira leitura, chamou a atençáo da turma e foi ensejo para que vivências com o trabalho informal (situaçâo vivida por Miralva) aparecessem nas sequências discursivas. Mas chamou a nossa atenção, particularmente, a Sequência discursiva desencadeada pela pergunta de Teresinha, que questionou a serventia de se dividir a torta em mais pedaços, mantendo a proporcionalidade do preço, que seria a abordagem típica em problemas da matemática escolar. Nessa situação, como analisamos, a matemática escolar foi confrontada, porque a lógica que a atividade tentou impor à vida cotidiana parecia não fazer sentido para Teresinha e para outras pessoas da turma. Os próprios alunos construíram uma significação que deu àquela situação condição de ser um ponto de recorrência que os apoiasse em seus processos de apropriação do conceito de fração equivalente.

O que ocorreu na outra turma pesquisada, a turma 80 , foi bem diferente do que ocorreu na turma 81. Naquela, não houve o mesmo envolvimento com a história de Miralva e a participação dos alunos se limitava, muitas vezes, a responder às perguntas que a professora fazia. $\mathrm{O}$ contraste entre as turmas mostrou, então, diferenças expressivas nos modos de participação e nas oportunidades de aprendizagem que foram criadas. $\mathrm{O}$ que explica essas diferenças, quando se trata de uma mesma professora desenvolvendo, em duas turmas, atividades muito semelhantes? Encontramos, em Vigotski, essa explicação, na relação entre instrução escolar e desenvolvimento.

Mas, para a compreensão dessa relação, é fundamental que se tenha em mente o que Vigotski chamava de instrução escolar, que diz respeito náo apenas às atividades escolares, mas à intencionalidade de quem as propóe e ao que acontece entre as pessoas que vivenciam aquelas atividades. Ao considerarmos adultos em processo de escolarização, não apenas a instrução escolar guiará o seu 
desenvolvimento, mas também todas as complexas vivências que os constituem como pessoas, pois, ambos, balizam o seus processos de autoinstrução e instrução.

A análise das sequências discursivas mostra como a cognição é social e situada, que não é algo que ocorre dentro das mentes das pessoas, mas, sim, nas relações sociais e por meio delas. É comum, no ensino de matemática, o uso de tortas ou pizzas para criar um contexto para o ensino de fraçóes. A história de Miralva, contudo, constituiu-se como um importante mediador semiótico para que alunos e alunas produzissem sentidos para aquela situaçáo e, consequentemente, para o conceito de fração equivalente. A etnografia da sala de aula, ao possibilitar emergir o ponto de vista dos participantes, revela como os alunos da EJA produzem significação para o que aprendem, numa perspectiva êmica e ética.

Entendemos que há que se ter coerência entre método e teoria adotados pelos pesquisadores. Essa coerência, segundo Pino (2005, p. 179), implica duas posturas metodológicas: "1) o objetivo da pesquisa não é a análise de fatos, mas de processos, ou seja, da história da gênese dos fatos [...] o que equivale dizer que o procedimento metodológico é histórico-genético; 2) contrapor à análise descritiva dos problemas a análise explicativa."

A pesquisa que descrevemos buscou essa coerência ao focalizar os processos de desenvolvimento, não um produto desse processo. E, também, ao buscar, pela construção de uma Etnografia em Educação em diálogo com a Psicologia Histórico-cultural, uma análise explicativa para esses processos, usando os conceitos de vivência e instruçáo escolar. Dessa forma, a abordagem teórico-metodológica, coerente com a perspectiva Histórico-cultural e com a Etnografia em Educação, deve ser: Contrastiva porque não se estabelece um padrão de comparação entre um fenômeno e outro, entre uma cultura e outra, mas, sim, analisam-se semelhanças e diferenças. Semelhanças, do ponto de vista externo, e profundas diferenças, do ponto de vista de sua gênese, essência e natureza. Interpretativa porque analisam-se indícios, pistas dos processos educacionais, não os processos em si mesmos. Dialética porque o que constitui esses processos "é o encontro de dois tipos de funçóes que se opóem e, ao mesmo tempo, constituem-se mutuamente" (PINO, 2005, p. 180), por exemplo, afeto e cognição, instrução escolar e desenvolvimento, fala e pensamento. Histórico-genética porque "o processo de cuja existência se procuram os indícios é um processo de geração de formas novas que tenham por base formas anteriores nas condições históricas concretas que definem o desenvolvimento da criança" (PINO, 2005, p.180) e, também, o desenvolvimento cultural dos adultos, sabendo que se desenvolver é um ato contínuo, inacabado.

Enfim, ensinar e aprender conteúdos escolares como Atividades Humanas (VIGOTSKI, 1983, 1995) e não apenas como aquisição de habilidades individuais. Atividades acontecem com pessoas, entre pessoas. Há um planejamento coletivo, 
para que todos possam participar e usufruir das oportunidades de aprendizagem do ensino de fraçóes, como o que aconteceu nessa sala de EJA.

\section{Referências}

AGAR, M. Language shock: Understanding the culture of conversation. New York: Macmillan, 2002.

AGUIAR, C. A. de et al. Coleçáo Viver, Aprender: Ensino Fundamental Contextos de vida e trabalho. $6^{\circ}$ ano, cap. 2, p. 353-372. São Paulo: Global Editora, 2012.

ARAÚJO, D. A. Vivência e instruçáo escolar: apropriação de conceitos matemáticos na EJA. 2017. Tese (Doutorado em Educação) - Faculdade de Educação, Universidade Federal de Minas Gerais, Belo Horizonte, 2017.

BAKHTIN, M.; VOLOCHINOV, N. V. Marxismo e filosofia da linguagem. 6. ed. São Paulo: Hucitec, 1992.

BAKHTIN, M. Estética da Criaçáo verbal. São Paulo: Martins Fontes, 2003.

BEZERRIL, G. S.; ACOSTA-PEREIRA, R. O conceito de cronotopo em Bakhtin e o círculo: Matizes Rabelaisianas. Intertexto, Uberaba: UFTM, v. 4, n. 2, p. 35-49, jul./dez. 2011.

BRANCO, S. M. Evolução das espécies, São Paulo: Editora Moderna, 1994.

CASTANHEIRA, M. L. et al. Interactional ethnography: an approach to studying the social construction of literate practices. Linguistics and Education, Norwood-NJ, v. 11, n. 4, p. 353-400, 2001.

DIAS, M. T. M. Leitura como atividade humana: "Pra que que a gente lê??". 2015. Tese (Doutorado em Educação) - Faculdade de Educação, Universidade Federal de Minas Gerais, Belo Horizonte, 2015.

GÓES, M. C. R. A abordagem microgenética na matriz histórico-cultural: uma perspectiva para o estudo da subjetividade. Cadernos Cedes, Campinas, n. 50, p. 9-25, abr. 2000.

GOMES, S. S. Limites e possibilidades do letramento escolar: um estudo etnográfico das capacidades de linguagem nas disciplinas curriculares. 2010. Tese (Doutorado em Educação) - Faculdade de Educação, Universidade Federal de Minas Gerais, Belo Horizonte, 2010. 
GOMES, M. F. C. Construindo relaçóes de inclusáo/exclusáo na sala de aula de química: histórias sociais e singulares. 2004. Tese (Doutorado em Educação) Faculdade de Educação, Universidade Federal de Minas Gerais, 2004.

GOMES, M.F.C.; DIAS, M.T. M.; VARGAS, P.G. Entre textos e pretextos: a produção escrita de crianças e adultos na perspectiva histórico-cultural. Belo Horizonte: editora UFMG, 2017.

GREEN, J. L.; DIXON, C.; ZAHARLIC, A. A Etnografia como uma lógica de investigação. Educaçáo em Revista, Belo Horizonte, v. 42, p. 13-79, dez. 2005.

JERESBTSOV, S; GOMEL. A cidade de L. S. Vigotski - pesquisas científicas contemporâneas sobre instrução no âmbito da teoria histórico-cultural de L. S. Vigotski. In: Veresk - Cadernos Acadêmicos Internacionais: Estudos sobre a perspectiva histórico-cultural de Vigotski - Brasilia: UniCEUB, 2014. p. 7-28.

OLIVEIRA, M. K. Cultura e Psicologia: questóes sobre o desenvolvimento do adulto. São Paulo: Editora Hucitec, 2009.

PINO, A. O conceito de mediação em Vygotsky e seu papel na explicação do psiquismo humano. In: GÓES, M. C.; PINO, Angel (Org.). Caderno Cedes, 24, Pensamento e linguagem: estudos na perspectiva da psicologia soviética. $1^{\circ}$ edição. Campinas, SP: Papirus, 1991. p. 32-43.

PINO, A. S. As marcas do humano: as origens da constituição cultural da criança na perspectiva de Lev S. Vigotski. São Paulo: Cortez, 2005.

PRESTES, Z. R. Quando náo é quase a mesma coisa. Análise de traduções de Lev Semionovitch Vigotski no Brasil. Repercussóes no campo educacional. 2010. 295 f. Tese (Doutorado em Educação) - Faculdade de Educação, Universidade de Brasília, Brasília, 2010.

SANTA BARBARA CLASSROOM DISCOURSE GROUP. Constructing literacy in classrooms: Literate action as social accomplishment. In: MARSHALL, H. (Ed.). Redefining student learning: Roots of educational change. Norwood, NJ: Ablex, 1992. p. 119-150.

SPRADLEY, J. P. Participant observation. New York: Holt, Rinehart and Winston, 1980.

VIGOTSKI, L.S.; LURIA, A. Estudos sobre a história do comportamento humano: os símios, o homem primitivo e a criança. Porto Alegre: Artes Médicas, 1996. 
VIGOTSKI, L. S. Obras Escogidas, v. I, Madrid: Aprendizaje/Visor, Terceira parte: El significado histórico de la crisis de la Psicología. Una investigación metodológica, 1995. p. 259-406.

VIGOTSKI, L. S. Obras Escogidas. v. II. Madrid: Aprendizaje/Visor, 1993.

VIGOTSKI, L. S. Obras Escogidas. v. III. Madrid: Aprendizaje/Visor, 1995.

VIGOTSKI, L. S. Vigotski - O Manuscrito de 1929: temas sobre a constituição cultural do homem. Campinas: Caderno Cedes, n. 71, Ediçâo Especial, 2000. 